\title{
The internal friction of lithium and sodium borophosphate glasses
}

\author{
Peter Hockicko ${ }^{1}$, Jana Mizeráková ${ }^{1}$, Francisco Muñoz ${ }^{2, *}$ \\ ${ }^{1}$ Department of Physics, Faculty of Electrical Engineering, University of Žilina, Slovakia \\ ${ }^{2}$ Institute of Ceramics and Glass (CSIC), Kelsen 5, 28049 Madrid, Spain \\ *Corresponding author, e-mail: fmunoz@icv.csic.es
}

\begin{abstract}
Alkali borophosphate glasses have recently gained strong interest, not only for their fundamental importance due to the mixed glass former effect but also because of their potential applicability as solid state electrolytes in energy harvesting devices. In the present work, internal friction measurements of lithium and sodium borophosphate glasses have been performed in order to look for further insights on the relationships between the ionic conduction mechanism and the structure of the glasses that has been previously determined. Absorption of acoustic waves shows two marked internal friction peaks with activation energy in the range of the activation energy for the ionic conduction of the glasses between 0.5 and $0.7 \mathrm{eV}$. Furthermore, the substitution of phosphorus by boron network former results in the decrease of the activation energy associated to both processes in parallel to the $\mathrm{E}_{\mathrm{a}}$ of the ionic conduction of alkali cations; and the relationship between the areas of both peaks suggests a change of the distribution of alkali ions between positions energetically different in agreement with the structural changes of the glass network.
\end{abstract}

Keywords: Borophosphate glasses; Solid Electrolytes; Acoustic attenuation; Internal friction; Ionic conduction 


\section{Introduction}

The internal friction of glasses has not traditionally been one of the mostly studied or easily accessible techniques to the glass research community. However, it can provide valuable results that, in conjunction with measurements of diffusion coefficients or impedance spectroscopy analysis of the conducting species, may allow one to distinguish and quantify between the different structural motifs of the glass networks. Basically, the internal friction measures the relaxations occurring around atomic positions after they are submitted to a stress. Thus, the classical peaks associated to atomic relaxations are due to the motion of cationic species, the interactions between different cations, including protons, and those from non-bridging oxygen atoms as well as the viscoelastic character of the network [1]. As it was studied in binary alkali silicate glasses, McVay and Day [2] showed that the internal friction curves of $\mathrm{Na}_{2} \mathrm{O}-\mathrm{Rb}_{2} \mathrm{O}-\mathrm{SiO}_{2}$ glasses presented two peaks: a first below $0^{\circ} \mathrm{C}$ and attributed to the alkali ions and a second near $200^{\circ} \mathrm{C}$ corresponding to the non-bridging oxygen atoms. In these mixed alkali glasses, they also observed the appearance of a third peak that was attributed to the mixed alkali effect when the two alkalis are present in the composition and as it was proved by means of diffusion coefficient measurements of the two alkalis. Other authors have instead studied the effect of dissolved water on the internal friction results, and demonstrated that the two usually observed peaks are affected by the amount of remaining water [3]. As the phosphate-based glasses are highly sensitive to hydration and may dissolve relatively large amounts of water, the authors proved that the presence of proton affects simultaneously both internal friction peaks reported in literature.

In alkali borate glasses, however, the first peak can be found at higher temperatures, above room temperature, and the agreement of the activation energies with those for the ionic conduction reveals that the relaxation mechanisms are the same as in silicate glasses [1]. In any case, the relaxations attributed to the more mobile species are seen at lower temperatures 
and present smaller activation energy, while those coming from structural units or cationic pairs have greater activation energy and appear at higher temperatures.

We have recently studied the acoustic attenuation and electrical properties of metaphosphate glasses [4] as well as of lithium oxynitride phosphate glasses, where part of the oxygen atoms is substituted by nitrogen atoms after a remelting reaction under flowing ammonia [5]. In all previous cases the attenuation spectra were simulated using the Double Power Law (DPL) function or Gaussian functions [4] and we obtained generally two peaks between room temperature and the glass transition temperature of the glasses, being attributed to relaxations of the modifier cations and with activation energies similar to those for the ionic conduction from impedance measurements. The analysis of the spectra turned out more complicated as the number of chemical environments or structural motifs of the network was increased. Furthermore, the sometimes observed overlapping of neighbouring peaks or very low energy relaxations of others makes the spectra to show a clear different number of peaks between compositions.

Lithium borophosphate glasses have notably been studied recently due to their interesting improved properties as a consequence of the mixed glass former effect (MGFE), through which the electrical conductivity, for instance, increases upon substitution of phosphorus by boron for constant $\mathrm{Li}_{2} \mathrm{O}$ containing glasses [6]. This has originated numerous studies concerning their usefulness as solid state electrolytes for lithium secondary batteries in either bulk or thin-film forms [7]. Meanwhile the absolute values of conductivity at room temperature are not as high as other solid electrolytes under use, these glasses are thought as potential candidates for a range of electrochemical devices that may profit of the advantages of glasses, such as chemical variability and homogeneity with absence of grain boundaries and simple preparation. Similarly, sodium borophosphate glasses do also present an increase 
of their conductivity in parallel with a decrease of the conduction activation energy as shown by Mizerakova et al. [8], and these could also find application in sodium ion batteries.

The MGFE phenomenon describes the nonlinear changes observed in glass properties, i.e. ionic conductivity or viscosity, upon the change in the fraction of two different glass former oxides while keeping the concentration of modifier oxide constant [6,9]. When $\mathrm{B}_{2} \mathrm{O}_{3}$ substitutes for $\mathrm{P}_{2} \mathrm{O}_{5}$, the boron atoms may be either four or three fold-coordinated in the form of $\left[\mathrm{BO}_{3}\right]$ or $\left[\mathrm{BO}_{4}\right]$ groups, respectively. The influence of the MGFE on the electrical conductivity of lithium borophophate glasses has been explained as a consequence of the formation of four-fold coordinated borate groups to which modifier cations, being either lithium or sodium, may be associated under a smaller electrostatic attraction [6], and has also been manifested in the behaviour of the viscosity and kinetic fragility [9]. Thus, the overall bonding of alkalis to non-bridging oxygens results smaller and gives rise to a net increase of the mobility of the alkali ions. The aim of the present work was to investigate the influence of the mixed glass former effect onto the internal friction of alkali borophosphate glasses with compositions $50 \mathrm{R}_{2} \mathrm{O}-\mathrm{xB}_{2} \mathrm{O}_{3}-(50-\mathrm{x}) \mathrm{P}_{2} \mathrm{O}_{5}(\mathrm{R}=\mathrm{Li}$ or $\mathrm{Na})$ by means of its relationships with the atomic structure of these glasses and their known properties such as electrical conductivity and viscosity.

\section{Experimental}

The lithium and sodium borophosphate glasses of the systems of composition $50 \mathrm{Li}_{2} \mathrm{O}-\mathrm{xB}_{2} \mathrm{O}_{3^{-}}$ $(50-\mathrm{x}) \mathrm{P}_{2} \mathrm{O}_{5}(\mathrm{x}=5,10,15,20,25,50)$ and $50 \mathrm{Na}_{2} \mathrm{O}-\mathrm{xB}_{2} \mathrm{O}_{3}-(50-\mathrm{x}) \mathrm{P}_{2} \mathrm{O}_{5}(\mathrm{x}=5,10,15)$ were prepared by the melting and quenching method. Glass batches for $100 \mathrm{~g}$ were obtained through mixing reagent grade raw materials, $\mathrm{Li}_{2} \mathrm{CO}_{3}$ and $\mathrm{Na}_{2} \mathrm{CO}_{3}$ (Sharlau, ACS), $\mathrm{B}_{2} \mathrm{O}_{3}$ (Panreac) and $\left(\mathrm{NH}_{4}\right)_{2} \mathrm{HPO}_{4}$ (Sharlau, ACS), being firstly calcined in porcelain crucibles up to $450^{\circ} \mathrm{C}$, then melted during $2 \mathrm{~h}$ at temperatures ranging from $800{ }^{\circ} \mathrm{C}$ to $1000{ }^{\circ} \mathrm{C}$ depending on their 
composition. The melts were poured onto brass moulds and annealed above their corresponding glass transition temperature. Chemical analysis through X-ray Fluorescence spectroscopy did not show variation of the nominal molar oxide contents, neither contamination from the ceramic crucibles.

After annealing, glass specimens were obtained through cutting and polishing as planeparalell plates of ca. $1 \mathrm{~cm}^{2}$ and sputtered with gold layers of $1 \mu \mathrm{m}$ thickness.

The conventional pulse-echo experimental equipment for measurement of acoustic attenuation and velocity was implemented in the investigation. Longitudinal acoustic waves with frequency $13 \mathrm{MHz}$ were produced by a HF pulse generator Matec 7700 . The sample was acoustically coupled to a piezoelectric transducer $\mathrm{LiNBO}_{3}$, which possesses the properties such large piezoelectric coefficient and very low acoustic losses.

The multiple reflections were observed, and generated signal was amplified and displayed on the oscilloscope. The velocity was measured from the transit time between the reflected pulses and their corresponding distance in the investigated samples. The attenuation was obtained from the amplitude of selected echoes received by attenuation recorder [10]. The consequential errors were minimized according McSkimin method [11].

The measured acoustic attenuation is dependent on temperature. The heating rate was 0.1 K. $\min ^{-1}$ and the raising temperature was monitoring by digital multimeter using a thermocouple (type T). Acoustic measurements were performed at temperatures below $\mathrm{T}_{\mathrm{g}}$ of the investigated glasses, in the range from $290 \mathrm{~K}$ to $550 \mathrm{~K}$.

Tan $\delta$ is called as internal friction or mechanical attenuation (electrical analogue), it represents the absorption of vibrational energy in a substance and is related to the vibrational (acoustic) spectrum [1].

$$
\tan \delta=Q^{-1}=\Delta \frac{\omega \tau}{1+\omega^{2} \tau^{2}}
$$


where $\omega$ is angular frequency and $\tau$ is relaxation time, the centred position of peak is given by expression $\omega \tau=1$. Internal friction analysis gives us the useful information about the structural relaxation of glass below $\mathrm{T}_{\mathrm{g}}$. Internal friction is defined with following equation:

$$
\phi=\alpha \lambda / \pi
$$

where $\alpha$ is the amplitude absorption coefficient per unit distance and $\lambda=\mathrm{v} / \mathrm{f}$.

\section{Results}

The acoustic absorption of longitudinal waves with frequency of $13 \mathrm{MHz}$ is represented in terms of the internal friction and depicted in Fig. 1 as a function of temperature for the investigated group of lithium borophosphate glasses. Broad peaks with characteristic temperatures of the maximum of absorption were observed. As it can be seen, the temperature of peak maxima (both at low and high temperatures) for lithium borophosphate system decreases for $\mathrm{B}_{2} \mathrm{O}_{3}$ contents up to 20 mol \%, then increases between 25 and 50 mol \% $\mathrm{B}_{2} \mathrm{O}_{3}$ contents.

Figure 2 shows the temperature dependence of the internal friction for the sodium borophosphate system where the temperatures of peak maxima decrease from 5 to 25 mol \% $\mathrm{B}_{2} \mathrm{O}_{3}$.

In most cases, the relaxation process in glass structure follows the Arrhenius law,

$$
\tau=\tau_{0} \exp \left(\frac{E_{a}}{k_{B} T_{\text {peak }}}\right),
$$

where $\tau_{0}$ is the pre-exponential factor (a relaxation frequency of ion hopping of $f_{0}=1 / \tau_{0} \sim$ $10^{14} \mathrm{~Hz}$ is generally used), $k_{B}$ is the Boltzmann constant and $T_{\text {peak }}$ is the temperature of peak maxima. 
One of the most acceptable assumptions for rigid materials is the distribution of activation energy and consequently the relaxation times. This distribution of relaxation times is often satisfactory given by a Gaussian function, and related to disordered materials [1] [12]. Assuming Gaussian distribution of activation energies [12], the experimental data were fitted with following expression:

$$
P(E)=\exp ^{\left[-\frac{1}{2}\left(\frac{E-E_{a}}{E_{0}}\right)^{2}\right]},
$$

where $E_{a}$ is activation energy evaluated from maximum temperature of friction peak and $E_{0}$ is the width of distribution.

The Eq. 4 was implemented for fitting of individual relaxation processes and calculation of activation energies for the high and low temperature peaks, see Fig. 3-5. Figure 6 shows the obtained values of activation energy for both the high (peak No. 1) and low temperature (No. 2) peaks in the temperature dependence of internal friction against the mol $\%$ of $\mathrm{B}_{2} \mathrm{O}_{3}$. For lithium borophosphate glasses it was observed a decreasing tendency of $E_{a}$ the higher temperature peak from concentration 0 up to 20 mol $\% \mathrm{~B}_{2} \mathrm{O}_{3}$ and then an increase up to 50 mol $\% \mathrm{~B}_{2} \mathrm{O}_{3}$. The $\mathrm{E}_{\mathrm{a}}$ of the lower temperature peak versus $\mathrm{B}_{2} \mathrm{O}_{3}$ content for lithium borophosphate glasses behaves according the similar manner. The obtained activation energies from internal friction spectra give similar behaviour with activation energies for conduction, calculated in [13].

The activation energies of internal friction of the high temperature peak of the sodium borophosphate glasses decreases between 5 and 25 mol \% $\mathrm{B}_{2} \mathrm{O}_{3}$ and the $\mathrm{E}_{\mathrm{a}}$ of the lower temperature peak versus $\mathrm{B}_{2} \mathrm{O}_{3}$ content for sodium borophosphate glasses behaves similarly (Fig. 7).

The experimental values of the velocities of longitudal acoustic waves and calculated values of activation energies for peaks No. 1 and 2 are listed in Table 1 together with the values of 
the activation energy for ionic conduction reported in references [6] and [4] for the lithium and sodium borophosphate series, respectively. The values of velocity show an increasing tendency for both lithium and sodium borophosphate glass series along with the increase of the boron content with the exception of 50Li15B glass, which exhibits a small deviation from this tendency. The velocity parameter affects the changes in magnitude of the internal friction peaks which change with composition.

\section{Discussion}

The results of activation energy plotted in Figs. 6 and 7 have clearly shown two characteristics of the internal friction measurements: the first is that the values associated to both peaks may be attributed to a similar relaxation mechanism as both vary similarly with the boron content and possess close activation energy values. The second is that their behaviour is marked by a non-linear trend in the lithium glasses, not seen however in the sodium borophosphate glasses due to the lack of data points above $25 \mathrm{~mol}_{\%} \mathrm{~B}_{2} \mathrm{O}_{3}$ and the particular absence of stable glass at the $50 \mathrm{~mol} \%$ composition for sodium. This non-linear variation is characteristic borophosphate systems as it was also observed in the ionic conductivity of the lithium glasses [6] or as in their kinetic fragility behaviour [9]. When studying the structure of lithium borophosphate glasses, the use of high field 1D/2D Nuclear Magnetic Resonance techniques allowed distinguishing a number of structural groupings that appear from the substitution of $\mathrm{P}_{2} \mathrm{O}_{5}$ by $\mathrm{B}_{2} \mathrm{O}_{3}$ glass formers [9]. Small additions of boron enter the network as $\mathrm{BO}_{4}$ tetrahedra fully surrounded by $\mathrm{P}$ atoms. However, as the boron content increases, at the expense of $\mathrm{P}$, the type of $\mathrm{BO}_{4}$ tetrahedra changes to new groups with higher number of $\mathrm{B}$ as second neighbours. Then, above an intermediate content of $\mathrm{B}_{2} \mathrm{O}_{3}$, ca. $15 \mathrm{~mol} \%$, the number of total $\mathrm{BO}_{4}$ starts decreasing due to the appearance of $\mathrm{BO}_{3}$ triangular motifs. That content is the one that clearly determines a change in the evolution of the glass properties and is thus 
responsible for the change in the trend of activation energy of internal friction observed in the lithium borophosphate glasses.

The two peaks could then in principle be associated to the relaxation of alkali cations given that both response similarly to the change in composition along with a decrease of their activation energy below 20 mol $\% \mathrm{~B}_{2} \mathrm{O}_{3}$, and their values of activation energy are very close to the values from conductivity measurements. On the other hand, as shown in [6] for a series of alkali and alkaline-earth metaphosphate glasses, the Raman shifts of the symmetric stretching vibrations from O-P-O bonds, that are characteristic of the strength of the bonds between non-bridging oxygens and phosphorus, followed the same trend that the activation energy of the highest temperature peak. The authors did not exclude a relationship between this peak and the mobility of the non-bridging oxygens of the network. However, in those metaphosphate glasses two peaks were also measured at different temperatures and with different activation energy, and they were attributed to alkali cations in at least two different structural positions. Furthermore, a non-linear change of the ratio between the areas of absorption peaks was thought to be due to a change in the population of the hopping positions of the respective modifier cations.

When analysing the activation energy for the ionic conduction in single alkali glasses ones usually only observes a single activation energy value that is attributed to the rate limiting process, or the hopping of the cations requiring the highest energy barrier that dominate the conduction process. However, acoustic attenuation and the present internal friction measurements may allow distinguishing between different thermally activated processes that correspond to cations in different structural positions. The ratio between the areas under low and high temperature peaks (A2/A1) against the molar content of $\mathrm{B}_{2} \mathrm{O}_{3}$ for the lithium and sodium borophosphate glass series has been plotted in Fig. 8. The data show a decrease of the A2/A1 ratio up to $15 \mathrm{~mol} \% \mathrm{~B}_{2} \mathrm{O}_{3}$ for the lithium borophosphate glasses and also a decrease 
up to $25 \mathrm{~mol} \% \mathrm{~B}_{2} \mathrm{O}_{3}$ for the sodium compositions. Further substitution of phosphorus by boron in the lithium glasses results in higher values of A2/A1 ratio. As it was shown by Muñoz-Senovilla et al. in [9], there is a marked change in the structure of the borophosphate glass network between 15 and 20 mol $\% \mathrm{~B}_{2} \mathrm{O}_{3}$, i.e. the proportion of $\mathrm{BO}_{4}$ groups starts decreasing while the one of $\mathrm{BO}_{3}$ visibly increased.

Therefore, meanwhile both peaks experience a decrease of their activation energy upon the addition of boron up to $15-25 \mathrm{~mol} \%$, their respective contents seem to be affected in a different manner as from the change in A2/A1 ratio and also influenced by the type of network structural groups and in agreement with the non-linear variation of the activation energy observed for the lithium glasses. This is then thought to be caused by the change in the distribution of the populations of the mobile cations between the two structural sites that account for the two internal friction peaks. When boron substitutes for phosphorus, the population of cations associated to peak No. 1 is increased at the same time that its average activation energy does also decrease; this taking place up to $15 \mathrm{~mol} \% \mathrm{~B}_{2} \mathrm{O}_{3}$ in $\mathrm{Li}$ glasses and $25 \mathrm{~mol} \%$ in $\mathrm{Na}$ ones.

\section{Conclusions}

The measurements of acoustic absorption and calculated internal friction values of lithium and sodium borophosphate glasses allowed us distinghising two peaks that are attributed to relaxation of modifier cations is dissimilar positions. The activation energy of both relaxation peaks decreases with the substitution of boron for phosphorus as it does the activation energy for the ionic conduction of the glasses, while in the lithium glass series shows a minimum at $15 \mathrm{~mol} \% \mathrm{~B}_{2} \mathrm{O}_{3}$ as it has also been previously observed when studying their electrical conductivity and fragility. Furthermore, when analysis the relationship between the areas under both such peaks, it is found that this experiments the same evolution that the activation 
energy of each of the peaks by separate. The last has been interpreted in terms of a change in the distribution of the modifier cations that are responsible for the ionic conduction.

\section{Acknowledgements}

The authors would like to thank F. Černobila for technical assistance. This study was supported by project VEGA No. 1/0510/17 and ITMS: 26220120046 co-funded from EU sources and European Regional Development Fund. F.M. thanks also funding from project MAT2017-87035-C2-1-P (AEI/FEDER, UE). 


\section{References}

[1] W.A. Zdaniewsky, G.E. Rindone and D.E. Day, J. Mat. Sci. 14 (1979) 763-775.

[2] G.L. Mcvay and D.E. Day, J. Am. Ceram. Soc., 53 (1970) 508-513.

[3] D.E. Day and J.J. Stevels, J. Non-Cryst. Solids, 14 (1974) 165-177.

[4] L. Muñoz-Senovilla, J. Biresova, P. Hockicko and F. Muñoz, J. Non-Cryst. Solids 440 (2016) 26-30.

[5] P. Hockicko, P. Bury and F. Muñoz, J. Non-Cryst. Solids, 363 (2013) 140-146.

[6] F. Muñoz, L. Montagne, L. Pascual and A. Durán, J. Non-Cryst. Solids, 355 (2009) 25712577.

[7] S. Lee, J. Kim, D. Shim, Solid State Ionics, 178 (2007) 375-379.

[8] J. Mizerakova, P. Hockicko and F. Muñoz, Communications - Scientific Letter of the Univesity of Zilina, 19 (2017) 46-50.

[9] L. Muñoz-Senovilla, G. Tricot and F. Muñoz, Phys. Chem. Chem. Phys., 19 (2017) $22777-22784$.

[10] P. Hockicko, J. Kúdelčík, F. Muñoz and L. Muñoz-Senovilla, Advances in Electrical and Electronic engineering 13 (2015) 198-205.

[11] P.D. Edmonds, Methods of Experimental Physics: Ultrasonics, New York : Academic Press, Inc. 19 (1981).

[12] M. Cutroni, A. Mandanici, E. Bruno, Physical Chemistry and Chemical Physics 4 (2002) 4539-4542.

[13] R. B. Christensen, PhD Thesis, Iowa State University (2012).

[14] L. Muñoz-Senovilla, PhD Thesis, Universidad Autónoma de Madrid (2016). 


\section{Figure captions}

Figure 1: Temperature dependence of internal friction for the investigated samples of the lithium borophosphate glasses measured at the frequency of $13 \mathrm{MHz}$.

Figure 2: Temperature dependence of internal friction for the investigated samples of the sodium borophosphate glasses measured at $13 \mathrm{MHz}$.

Figure 3: Internal friction for the investigated samples of the lithium borophosphate glasses from 5 to $15 \mathrm{~mol} \% \mathrm{~B}_{2} \mathrm{O}_{3}$ with the obtained best fit of individual processes.

Figure 4: Internal friction for the investigated samples of the lithium borophosphate glasses from 20 to $50 \mathrm{~mol} \% \mathrm{~B}_{2} \mathrm{O}_{3}$ and fits of individual processes.

Figure 5: Internal friction for the investigated samples of the sodium borophosphate glasses for 5 to $25 \mathrm{~mol} \% \mathrm{~B}_{2} \mathrm{O}_{3}$ with best fits.

Figure 6: Activation energies for the high temperature peak 1 (full square) and low temperature peak 2 (empty square) of lithium metaphosphate glass and lithium borophosphate glasses as a function of the $\mathrm{B}_{2} \mathrm{O}_{3}$ content. Lines are drawn as a guide for the eyes.

Figure 7: Activation energies for the high temperature peak (full square) and low temperature peak (empty square) of sodium metaphosphate and sodium borophosphate glasses as a function of the $\mathrm{B}_{2} \mathrm{O}_{3}$ content. Lines are drawn as a guide for the eyes.

Figure 8: Ratio between the areas of the low (A2) and high temperature (A1) internal friction peaks as a function of the $\mathrm{B}_{2} \mathrm{O}_{3}$ content for lithium (full square) and sodium borophosphate glasses (empty square). Lines are drawn as a guide for the eyes. 


\section{Table captions}

Table 1: Velocity and activation energies for the first (high temperature) and second (low temperature) peaks in $\mathrm{Li}$ and $\mathrm{Na}$ borophosphate glasses, and activation energy for ionic conduction in lithium borophosphates (taken from reference [6]) and sodium glasses (values from reference [8]).

Table 1

\begin{tabular}{|c|c|c|c|c|}
\hline Sample & $\begin{array}{c}\mathrm{v} \\
{[\mathrm{m} / \mathrm{s}]}\end{array}$ & $\begin{array}{c}\mathrm{E}_{\mathrm{a}} \text {-Peak 2 } \\
{[\mathrm{eV} \pm 0.01]}\end{array}$ & $\begin{array}{c}\mathrm{E}_{\mathrm{a}}-\text { Peak 1 } \\
{[\mathrm{eV} \pm 0.01]}\end{array}$ & $\begin{array}{c}\mathrm{E}_{\mathrm{a}} \text { conduction } \\
(\mathrm{eV})\end{array}$ \\
\hline $50 \mathrm{Li}$ & n.d. & 0.67 & 0.73 & 0.83 \\
\hline 50Li5B & 5008 & 0.56 & 0.63 & 0.75 \\
\hline 50li10B & 5049 & 0.52 & 0.61 & 0.67 \\
\hline 50Li15B & 5479 & 0.50 & 0.57 & 0.67 \\
\hline 50Li20B & 5345 & 0.49 & 0.55 & 0.63 \\
\hline $50 \mathrm{Li} 25 \mathrm{~B}$ & 5476 & 0.53 & 0.6 & 0.67 \\
\hline 50Li50B & 6648 & 0.54 & 0.71 & $0.65^{*}$ \\
\hline $50 \mathrm{Na}$ & n.d. & n.d. & 0.69 & 0.77 \\
\hline $50 \mathrm{Na} 5 \mathrm{~B}$ & 4214 & 0.60 & 0.71 & 0.76 \\
\hline $50 \mathrm{Na} 15 \mathrm{~B}$ & 4220 & 0.56 & 0.63 & 0.70 \\
\hline $50 \mathrm{Na} 25 \mathrm{~B}$ & 4643 & 0.48 & 0.55 & 0.67 \\
\hline
\end{tabular}

(*) Measured following method as described in ref. [6].

(n.d.) Not determined 


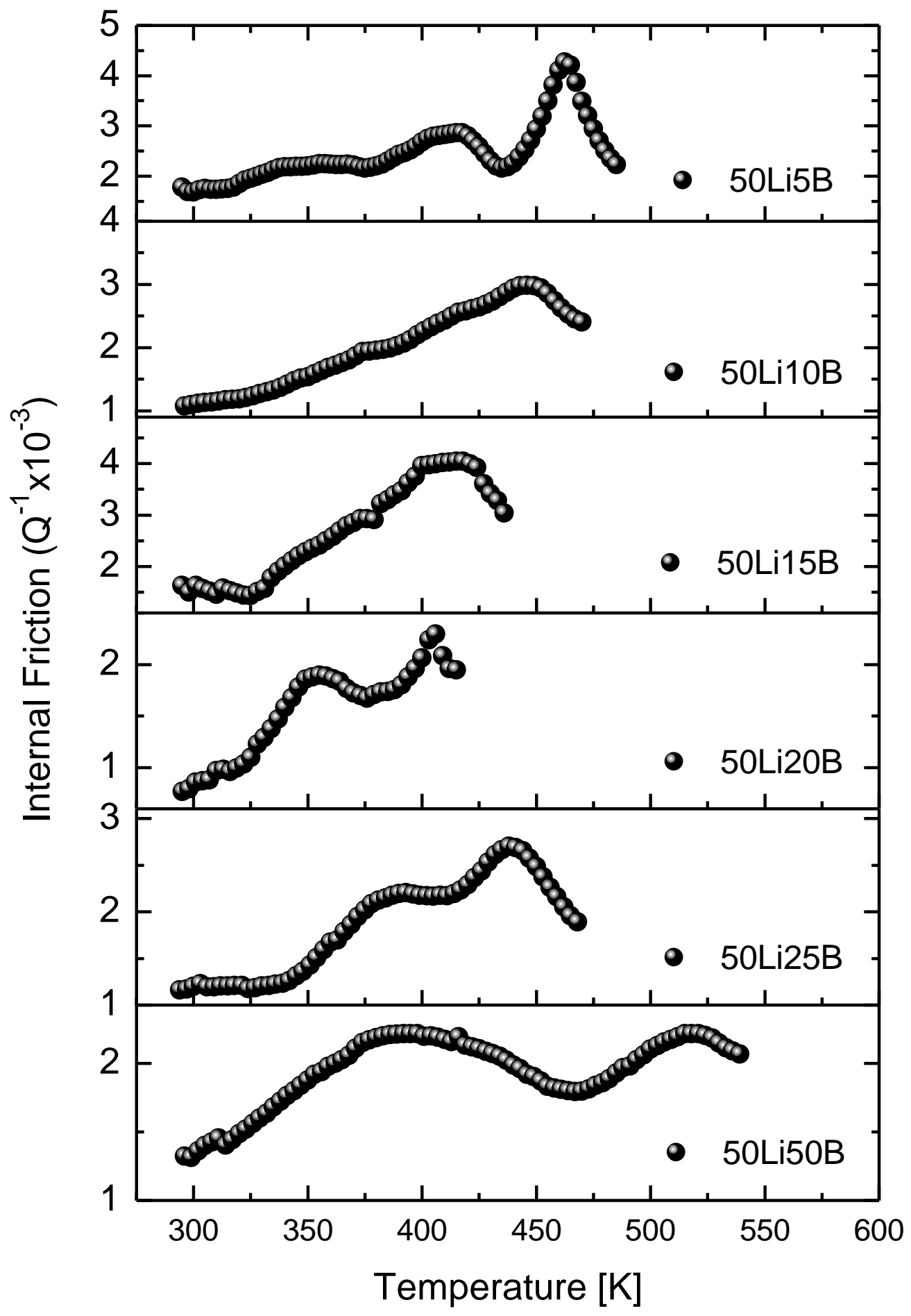

Figure 1 


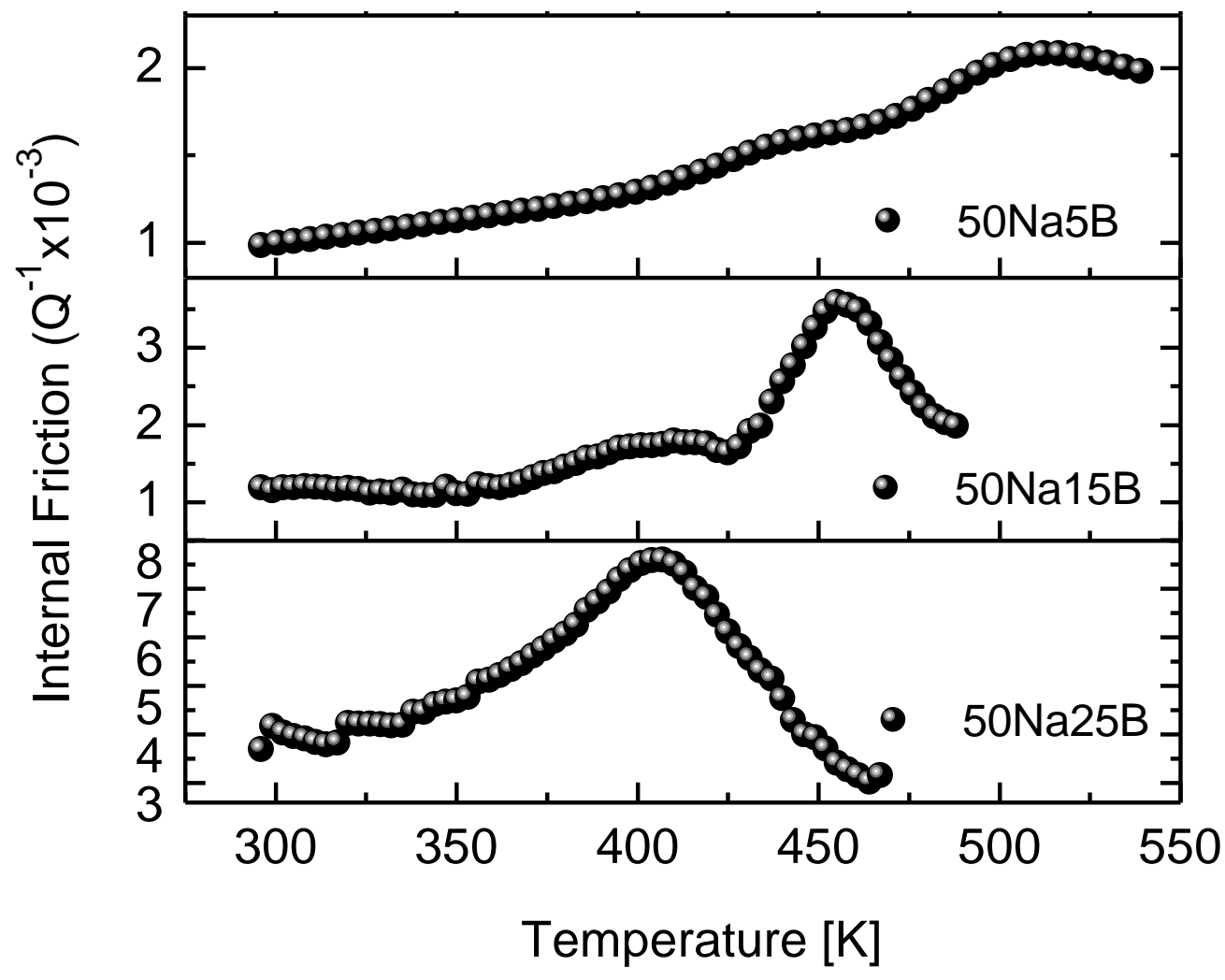

Figure 2 


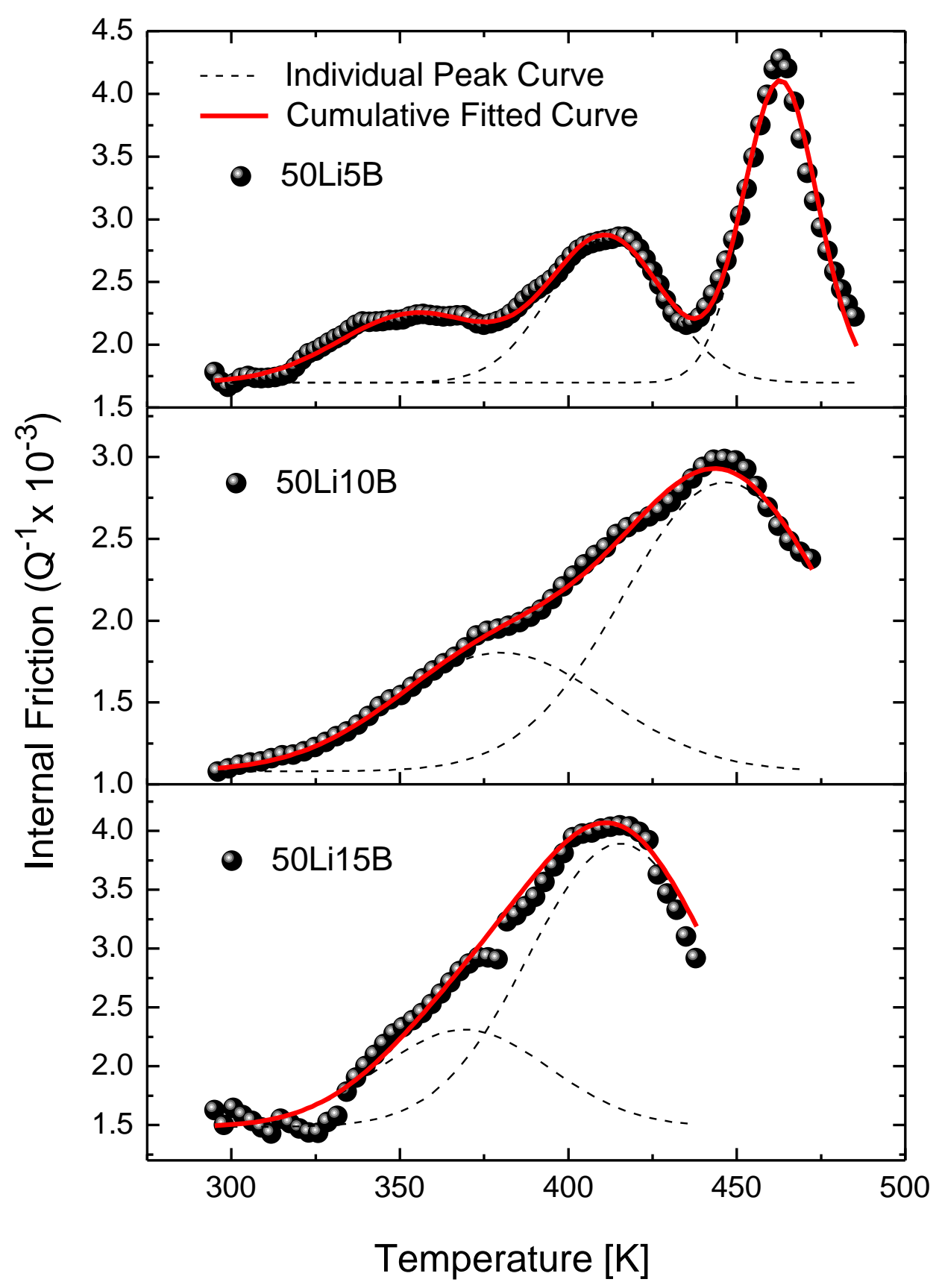

Figure 3 


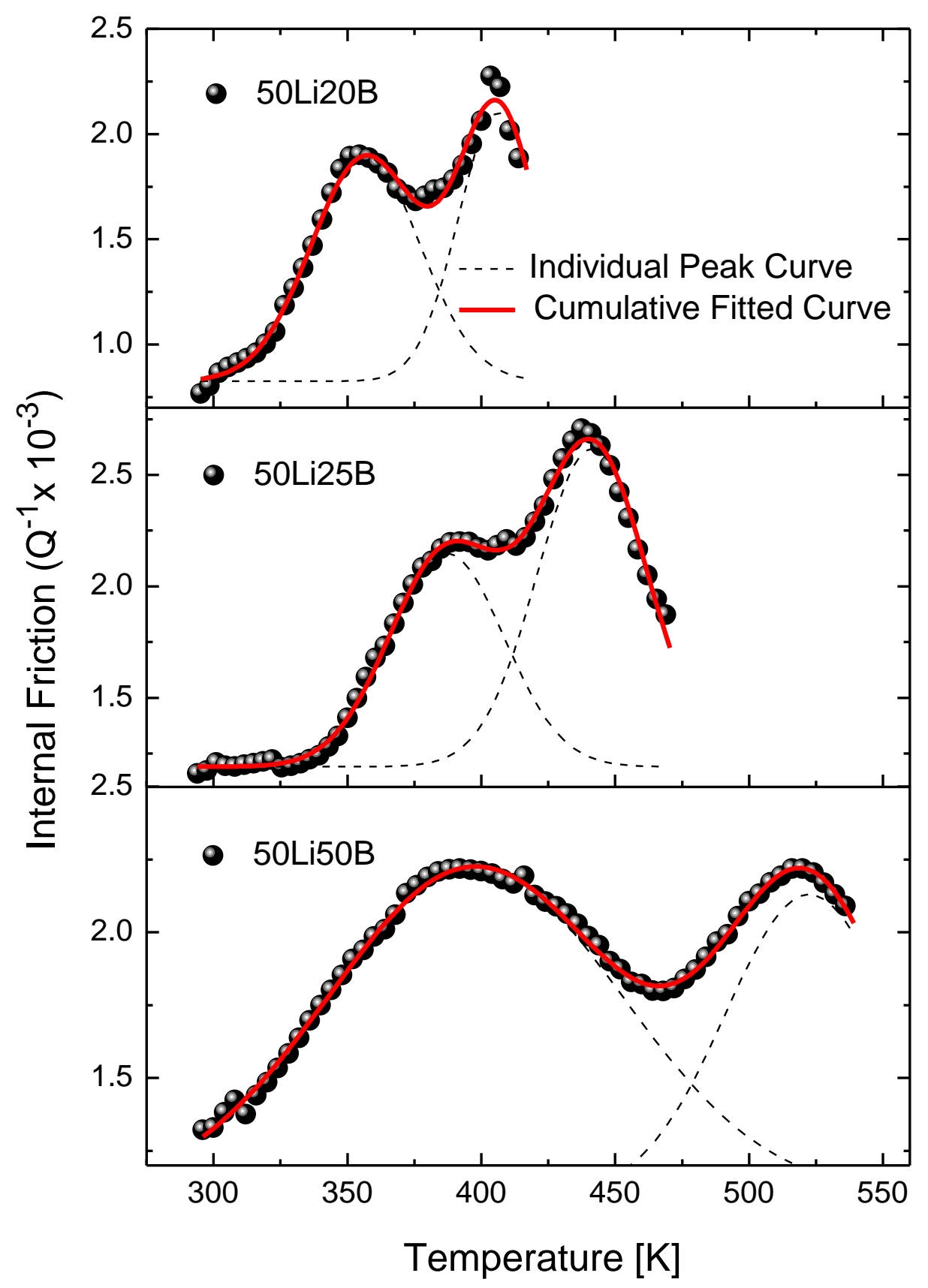

Figure 4 


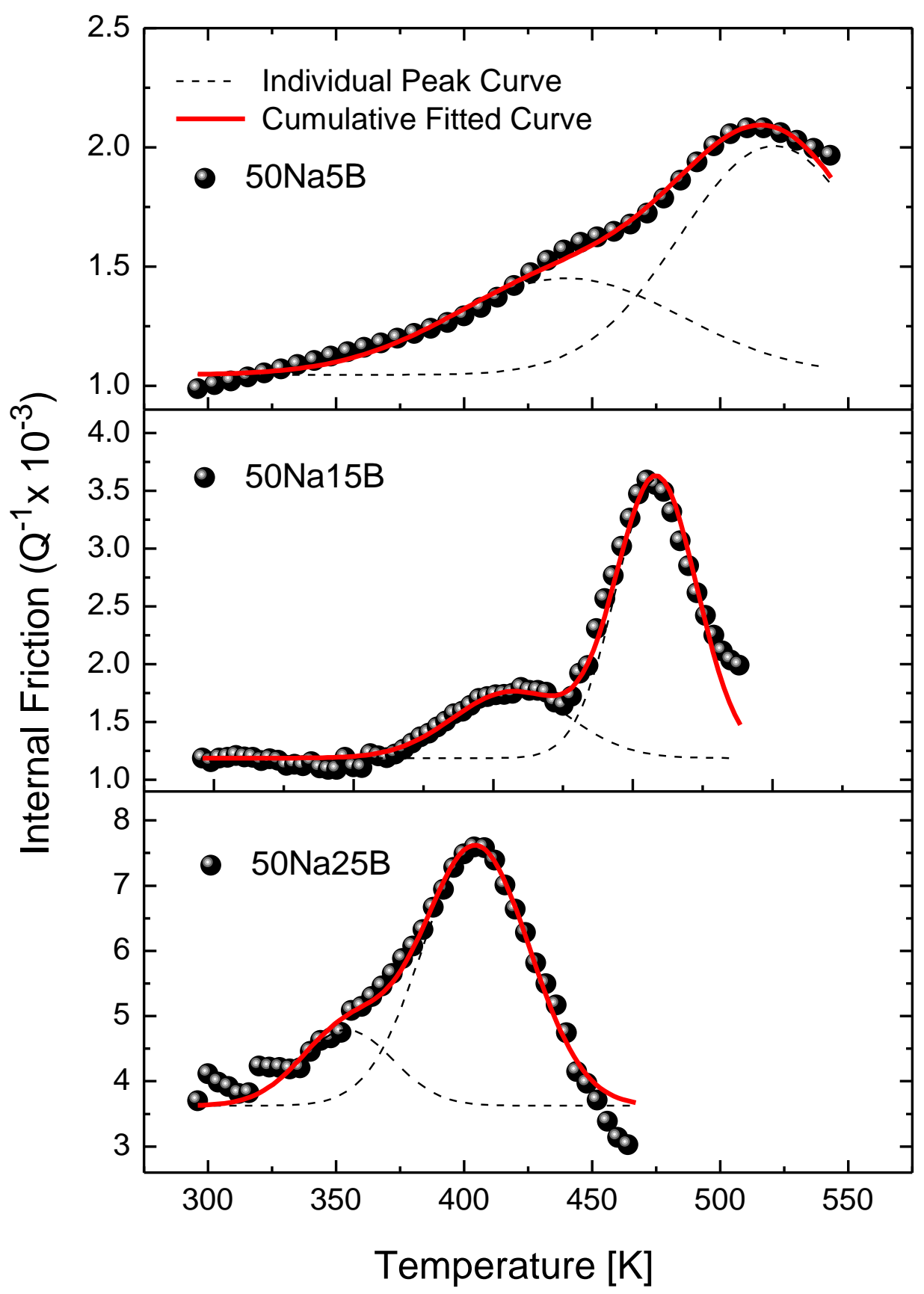

Figure 5 


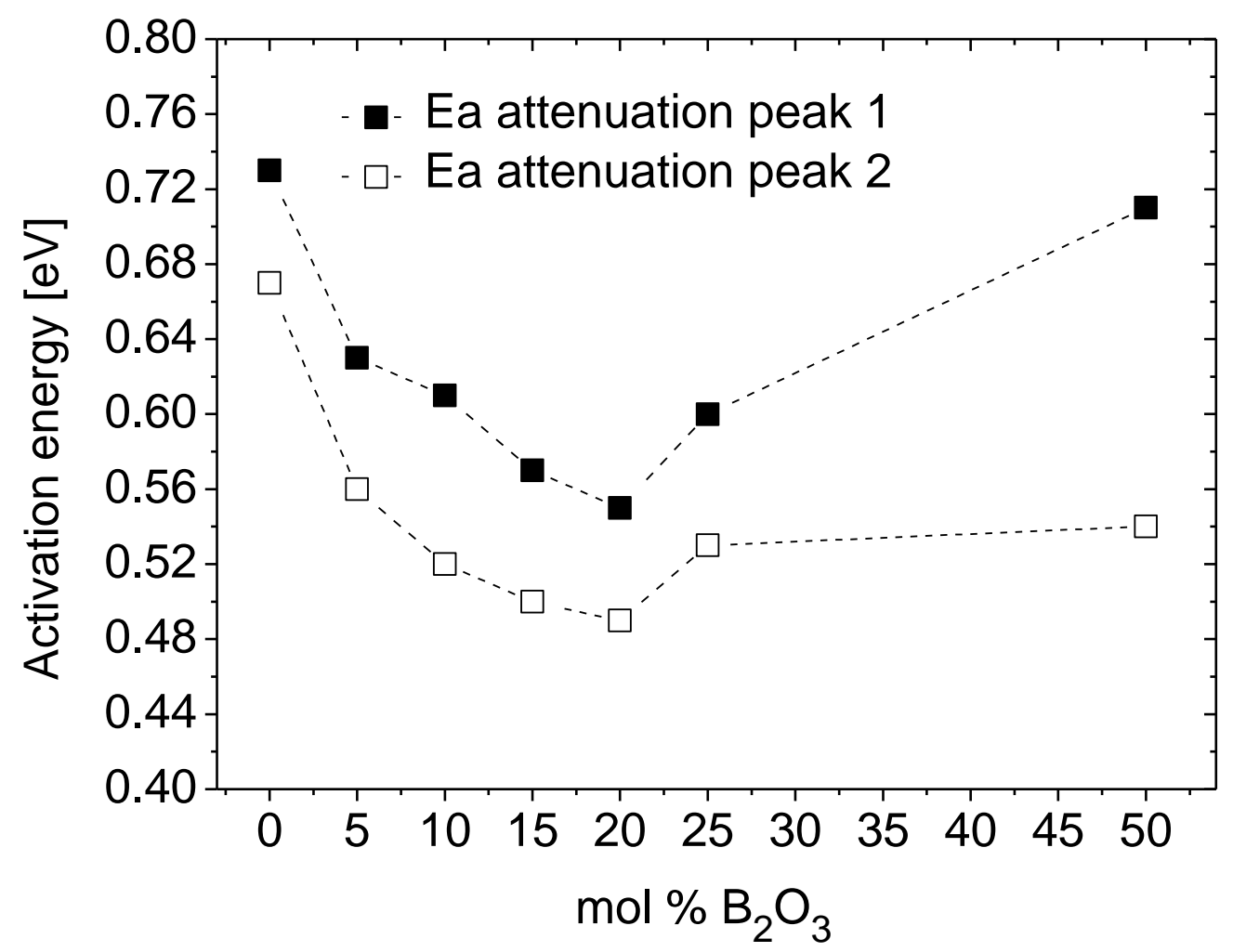

Figure 6 


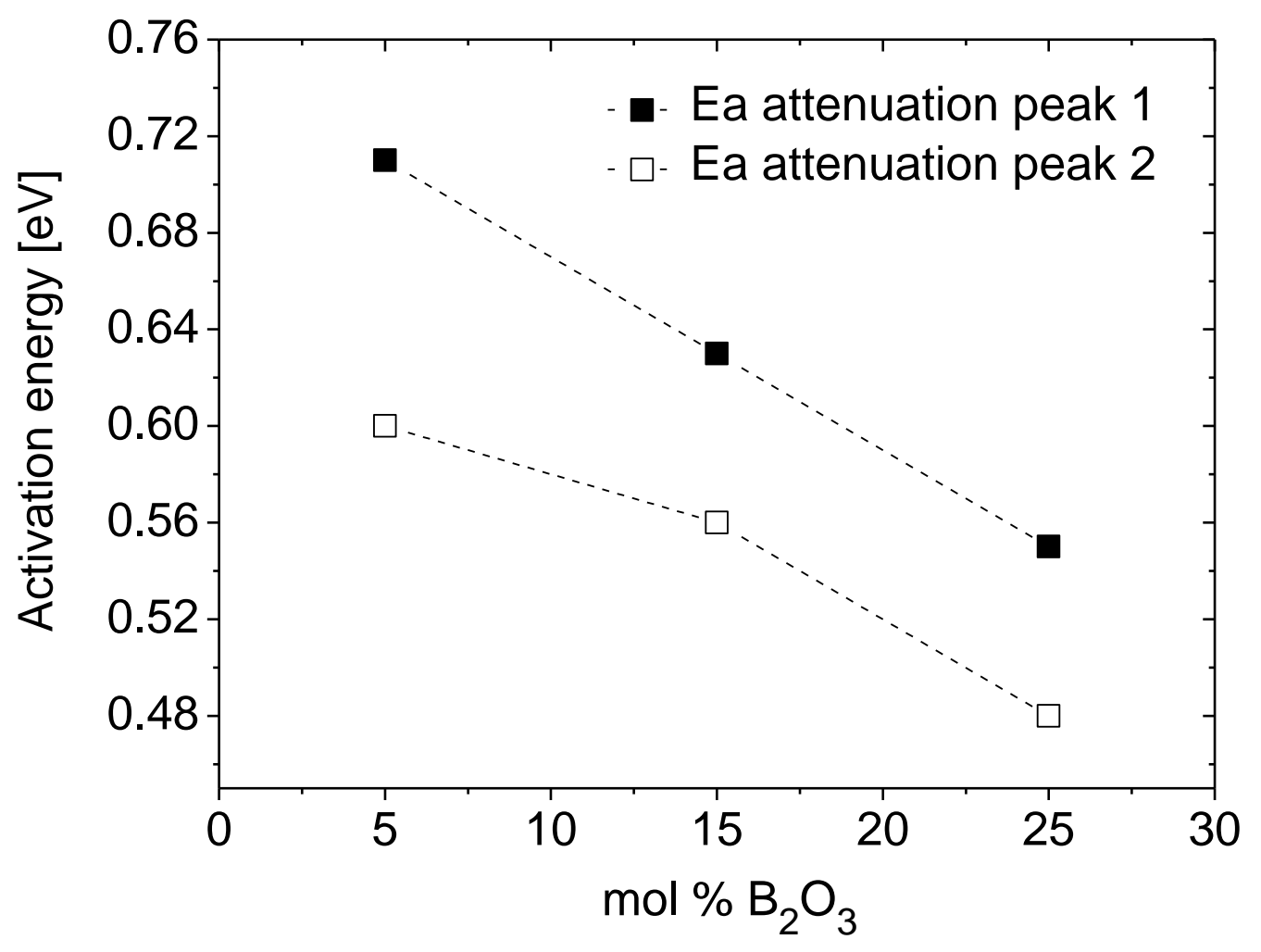

Figure 7 


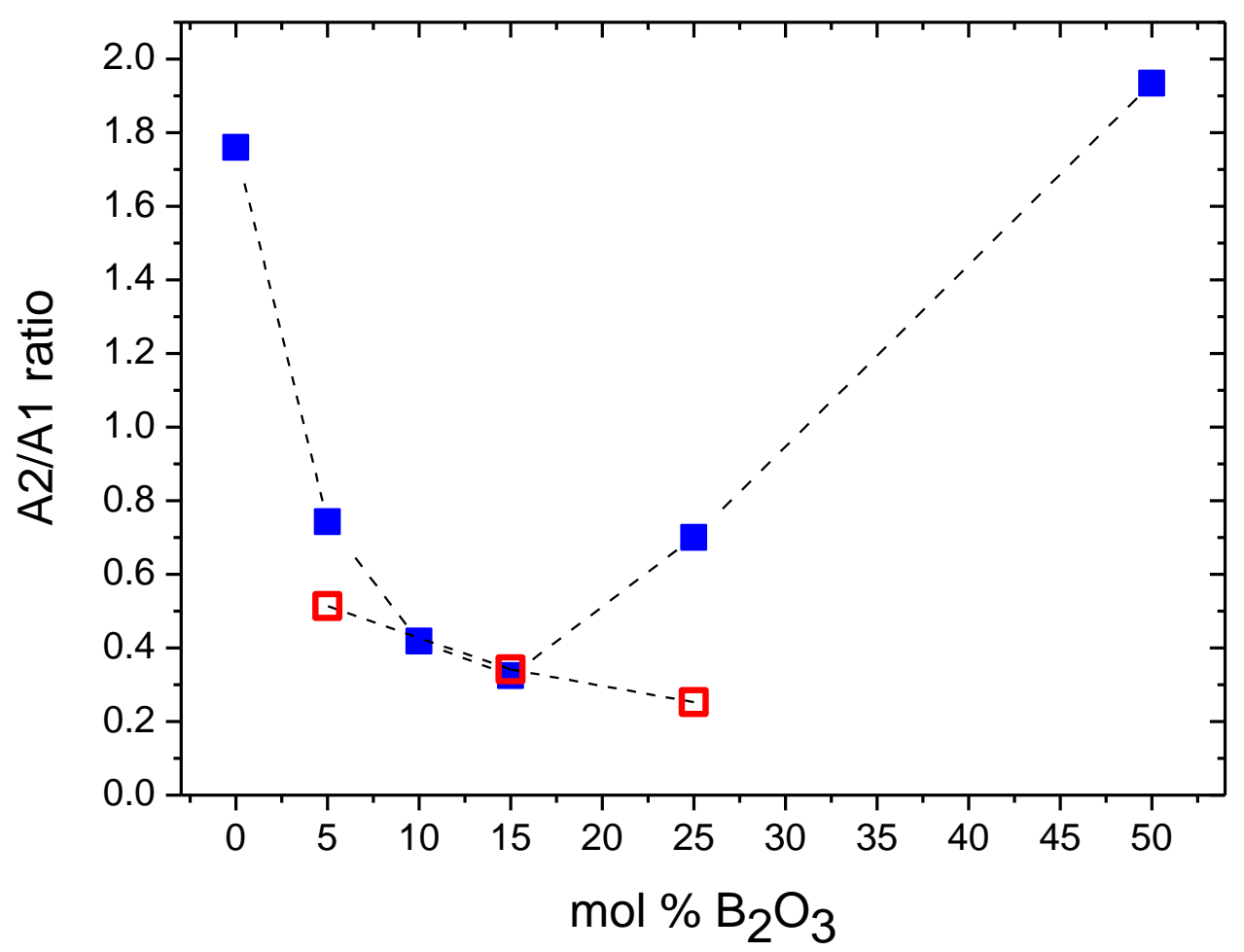

Figure 8 